children living on supplementary benefit the average weekly shopping basket was likely to be deficient in energy and fibre and high in fat and salt and the children's diets deficient in iron and calcium. This was so despite the fact that the investigators chose foods from a large supermarket, selecting only the cheapest brands and making no allowance for waste. This weekly shopping basket contained no "packaged convenience foods," except canned corned beef, beefburgers, and fish fingers, and cost $£ 30.50$, representing $41 \%$ of the household budget.

The key to understanding the relation between income and the affordability of a healthy diet lies in the National Food Survey. For the well off a switch to a diet meeting current healthy eating guidelines may well mean a cut in the cost of the food budget but for poorer people the reverse is true, the increase having recently been estimated to be $35 \% .^{2}$

"Look After Your Heart" is the first campaign launched by the new Health Education Authority. It does indicate some political concern for the plight of the British and their diet, but emphasises only "victim blaming" individual solutions. ${ }^{3}$ Preventive health policy must go beyond exhortations to switch to (high saturated fat) mutton stew, well meaning though they may be.

E J BRUNNER

London Food Commission,

London ECIV 9AR

1 Bradshaw J, Morgan J. Budgeting on benefit: the consumption of families on social security. London: Family Studies Policy Centre, 1987.

2 Cole-Hamilton I, Lang TM. Tightening belts: a report on the impact of poverty on food. London: London Food Commission, 1986. 3 Brunner EJ. Looking at 'Look After Your Heart.' London: London Food Commission, 1987.

\section{Inequalities in health in Britain: specific explanations in three Lancashire towns}

SIR,-I was interested in the provocative article by Professor D J P Barker and Dr C Osmond (21 March, p 749) linking socioeconomic conditions in three neighbouring Lancashire towns in the earlier part of this century with current mortality for ischaemic heart disease, chronic bronchitis, stroke, and bronchopneumonia. These diseases together explained $80 \%$ of the large excess in all cause mortality for Burnley. May I suggest alternative explanations for such mortality, which might be confirmed from data that the authors have not published.

Inspection of table IV shows that there is no general pattern to the differences among the three towns. Only one condition-pneumonia-even roughly parallels the all cause mortality gradient. The large excess of mortality between Nelson (low) and Burnley (high) seems to be due to differences in standardised mortality ratios for ischaemic heart disease (63\% of the Burnley excess deaths), bronchitis, lung cancer, stroke, stomach cancer, and "other causes." If standardised mortality ratios for lung cancer are taken to be a reasonable index of cigarette smoking history Burnley (100) has a considerable excess over Nelson (81) and Colne (83). Similarly, the respective ratios for bronchitis (188, 134, and 132) and pneumonia $(174,108$, and 125) parallel these rates. In Burnley and Colre ischaemic heart disease ratios are equal $(120,119)$, while they are lower in Nelson (106). The ratios for stroke follow exactly the same pattern (Burnley and Colne 120 and 121, Nelson 101).

There is thus no close parallel with the neonatal, postneonatal, or social data when causes of death are considered separately. On the other hand, there is a parallel between lung cancer and respira- tory related deaths and a different pattern for vascular deaths. If cigarettes are the link for the "respiratory" standardised mortality ratios what might be the link for the "vascular" ratios? Vascular disease is multifactorial, but it has powerful genetic and dietary components. The authors state that the genetic stock of Nelson (low mortality) is different from Burnley and Colne, being largely "rural immigrants from Yorkshire, sturdier and healthier."

Is any information available from local blood transfusion data about $\mathrm{ABO}$ blood groups to complement the data from Mitchell on the strong association between ischaemic heart disease and genes in England, Wales, and Scotland?' Do the authors have any data on differences in cigarette smoking or diet, or both, between these towns?

Without these answers, I believe that their case is intriguing but unproved. I submit that postnatal environmental influences, such as diet and cigarettes (which have strong links with social factors), together with genetic influences, migh better explain these arresting data.

Peter Sleight

John Radcliffe Hospital,

Oxford OX3 9DU

1 Mitchell JR. An association between ABO blood group distribution and geographical differences in death rates. Lance 1977;i:295-7.

AUTHORS' REPLY, - We do not have data on cigarette smoking. Standard mortality ratios for lung cancer, however, are 85 (Nelson), 89 (Colne), and 105 (Burnley) among men aged 55-74 years and 73 78 , and 91 , respectively, among women. This indicates that cigarette smoking is well below the national average in the three towns, except among men in Burnley, where it is a little above. Hence it is most unlikely that smoking accounts for the remarkably high standardised mortality ratios from chronic bronchitis: 134, 119, and 171 among men and 156, 212, and 280 among women. A similar argument applies to pneumonia. In an earlier paper we set out the evidence that acute lower respiratory infection in early childhood has a greater influence than cigarette smoking in determining the geographical differences in chronic bronchitis throughout England and Wales.'

There are no comparative data on diet in the towns. We would be interested to know what evidence persuades Professor Sleight that the large geographical differences in ischaemic heart disease and stroke in Britain could be determined by differences in adult diet.

We did not state that "the genetic stock of Nelson is different." Rather, we wrots that "the people were recent migrants from nearby rural areas rather than second or third generation industrial workers." The better physique and health of the mothers is more likely to have environmental than genetic causes. Previous analyses have shown that variation in genetic influences, as indicated by the ABO genes, could explain only a small part of the variation in ischaemic heart disease and stroke mortality in Britain. ${ }^{2}$

We thank Professor Sleight for his response to our paper, but we hope that he will reconsider the commonly held view that the inequalities in health in Britain can be explained by cigarette smoking adult diet, and genes. There is increasing evidence of the importance of past differences in materna and child health, and this merits further investigation. It does not preclude influences in adult life.

\section{J P BARKER} COSMOND

Medical Research Council Environmental Epidemiology Unit, University of Southampton, Southampton SO9 4XY
1 Barker DJP, Osmond C. Childhood respiratory infection and adult chronic bronchitis in England and Wales. $\mathrm{Br} \mathrm{Med} \mathcal{J}$ 1986;293:1271-5.

2 Hewitt D, Anderson TW. ABO distribution and geographical differences in death rates. Lancet 1977;ii:298.

\section{Breadth versus depth}

SIR,-Writing a book review is difficult. It is necessarily subjective and we should not complain when Dr David Blaney, reviewing our book on infectious diseases (11 April, p 967), finds the chapter on immunisation "confusing" while a reviewer in another journal states that the very same chapter is "well written." Nor can we complain if Dr Blaney finds the book "unhelpful" when another says that the new general practitioner will find "much practical advice" and old hands will find it "interesting reading." Suffice it to say that we can have only biased views.

Dr Blaney makes the statement that breadth is no substitute for depth. The philosophy underlying our work was produced by turning this statement the other way round. Experience with the problems faced by trainee general practitioners has satisfied both of us that it is not a lack of detailed knowledge about infectious diseases that leads to bad management in general practice. For example, they know (from in depth studies) that antibiotics have no value in upper respiratory tract infections in children in winter, and yet time and time again we find that antibiotics are prescribed for such infections. We believe that this has to do with the lack of alternative management ideas and strategies. We deliberately set out to achieve breadth at the expense of depth. Knowing that there are many volumes on infectious diseases that general practitioners can refer to, we wanted to produce a book that was geared to management and easy to read and that contained practical strategies for general practitioners faced with patients with infections.

Whether we have succeeded remains a matter of opinion, but there is in our view nothing wrong with the philosophy. Looking down a long focus lens at general practice can produce a view of the world that is limited in usefulness unless it is balanced by a divergent view that takes in the ideas, concerns, and expectations of both patient and doctor.

\section{BROOKS} E DUNBAR

Peterloo Medical Centre,
Manchester M24 4DZ

$$
\text { 1987;37:1360. }
$$

Effect of protein restriction in insulin dependent diabetics at risk of nephropathy

SIR,-Dr David Cohen and colleagues (28 March, p 795) have shown convincingly that protein restriction may reduce the rate of albumin excretion in insulin dependent diabetics with microalbuminuria. Their speculations about the mechanism of the reduced rate, however, are based on observations that will need to be repeated using more appropriate methods.

Firstly, their estimate of the influence of the reduced glomerular filtration rate is based on the ratio of albumin clearance to edetic acid clearance. By calling this ratio "fractional albumin clearance" they imply that both clearances were measured concurrently, but as the albumin excretion rate was measured in overnight collections this was almost certainly not done. It is therefore possible that the fall in excretion rate owed more to a reduced glomerular filtration rate, and less 
to changes in the ultrafiltration properties of glomeruli, than they suggest.

Secondly, their conclusion that increased tubular reabsorption of albumin did not contribute to the fall in excretion rate is based on the absence of any consistent change in the observed rate of $\beta_{2}$ microglobulin excretion. It has been shown, however, that $\beta_{2}$ microglobulin is unstable in urine within a $\mathrm{pH}$ range $(\mathrm{pH}<5.5)$ common in overnight urine. ${ }^{12} \mathrm{~A}$ significant tubular contribution to the fall in excretion rate may not, therefore, be ruled out.

We do not, however, disagree with the authors' conclusion that protein restriction may help to preserve renal function in insulin dependent diabetics with microalbuminuria.

Wessex Regional Renal Unit,

A Polak

Portsmouth PO3 6AD

Southampton General Hospital,

D Rowe

Southampton

1 Bernard AM, Morean D, Lanwerys R. Comparison of retinolbinding protein and $\beta_{2}$-microglobulin determination in urine for the early detection of tubular proteinuria. Clin Chem Acta for the early detec

2 Davey PG, Gosling P. $\boldsymbol{\beta}_{2}$-Microglobulin instability in pathological urine. Clin Chem 1982;28:1330-3.

Infection by airborne Chlamydia trachomatis in a dentist cured with rifampicin after failures with tetracycline and doxycycline

SIR,-Professor M Midulla and colleagues (21 March, p 742) describe three patients, a doctor, his wife, and their dentist, all with chlamydial ophthalmia. It was not made clear whether husband and wife were treated simultaneously to prevent reinfection, nor is there any mention of other sexual partners and whether they were treated. Furthermore, it is unclear what criteria were used to assess whether treatment was ineffective with oral tetracycline or doxycycline. Was this conclusion based on clinical or microbiological results? After treatment with oral tetracycline clinical signs in severe chlamydial ophthalmia may take several months to resolve completely. If a micro-organism is to be deemed resistant to an antibiotic it would be appropriate to confirm resistance by in vitro tests. There is as yet no confirmed report of tetracycline resistance either in vitro or in vivo. In vitro studies have, however, shown rapid acquisition of resistance to rifampicin. ${ }^{1}$ Rifampicin should be reserved for treatment of mycobacterial infection, and in cases of apparent tetracycline failure erythromycin is a more appropriate alternative.

It is most unusual to presume that the doctor could still be shedding Chlamydia trachomatis and infecting his dentist after 10 days treatment with oxytetracycline and a further five days of doxycycline. We have performed microbiological follow up on hundreds of patients with chlamydial conjunctivitis and genital infection who were treated with oxytetracycline, doxycycline, or erythromycin and have yet to come across a resistant case. We have witnessed apparent failures of treatment, but in all cases this was due to reinfection.

Finally, the title of the article is misleading as airborne infection is not proved. The dentist's gloved fingers may have been contaminated with the doctor's saliva and may even have touched his ocular discharge. Assuming that the secretions were still infective, the organism could then have been accidentally inoculated into the dentist's own eye. Though chlamydial isolation from the dentist's urethral specimen was negative, there was no mention whether he had non-specific urethritis, which may be negative for chlamydia in such patients. ${ }^{2}$ Until chlamydial genital infection has been excluded in the dentist's sexual partners, we would question the actual mode of spread; the generalised assumptions in the paper raise too many unanswered questions.

mala Viswalingam BENG T GOH

JANET MANTELL

Moorfields' Eye Hospital, London ECIV 2PD

JOHN TREHARNE

Institute of Ophthalmology London

1 Keshishyean $\mathrm{HL}$, Jawetz E. Emergence of rifampin resistance in Chlamydia trachomatis. Nature 1973;244:173-4.

2 Mantell J, Goh BT. Occult chlamydial ophthalmia in men with non-gonococcal urethritis. BrMed f 1987;294:707.

AUTHORS' REPLY, - Pressure of space prevented us from describing other important details in the cases we presented.

The chronology of infection in the three cases was as follows: the first to become ill was the patient in case 1 , who, by attending our laboratory, probably accidentally contracted the conjunctiva infection due to Chlamydia trachomatis. He then transmitted the conjunctival infection to his wife, and subsequently, through sexual relations, the infection spread to their orogenital areas. The initial treatment with tetracycline was carried out simultaneously in these two patients, who were well instructed by us on the pathogenesis of infection due to chlamydia. Consequently, we reject the hypothesis of possible reinfection between them, the possibility of reinfection from other sexual partners is also to be discarded.

The dentist (case 3 ) stated that he did not notice any symptoms of urethritis and that he had no sexual relations with his fiancée, whose ocular and pharyngeal cultures yielded negative results fo $C$ trachomatis. Fifteen days before the doctor's dental visit the dentist had undergone a week's tetracycline treatment for a furuncle in his scalp. The doctor informed the dentist of the nature of his chlamydial infection, and the dentist was thus very careful not to make any manual contact between the infected secretions of his patient and his own mucosa.

Ours are only clinical observations, but can Dr Viswalingam and coworkers be certain that the failures that they have encountered originated from reinfection and not from antibiotic resistance? We chose rifampicin because of our broad, positive experience with this drug in cases of neonatal pneumonia and urogenital infection in mother treated unsuccessfully with erythromycin. In addition, resistance has been reported for erythromycin.

In our report we took into consideration not the resistance to antibiotics in vitro but the therapeutic failure that we verified by the persistence of the symptoms and by the positive laboratory results, which became negative in all three cases after treatment with rifampicin. We believe that questions remain about the route of transmission of infection due to $C$ trachomatis.

MaRio Midulla Daniela Sollecito Franco Feleppa ANNa Maria ASsEnSIO STEFANO ILAR

\section{La Sapienza University and}

CNR Institute of Experimental Medicine,

$$
\text { Rome, }
$$

Rome,

1 Mourad A, Sweet RL, Sugg N, Schachter J. Relative resistance to erythromycin in Chlamydia trachomatis. Antimicrob Agents Chemother 1980;18:696-8.
Pinch skin grafting or porcine dermis in venous ulcers

SIR,-Mr K R Poskitt and colleagues describe their experience with pinch grafts on the reepithelialisation of lower leg ulcers (14 March p 674). Though they interpreted the pathogenesis of the lesions in terms of impaired "diffusion of oxygen and metabolites," their treatment did not attempt to correct this problem. As graft survival depends on obtaining a vascular supply, ${ }^{1}$ impaired blood flow in the ulcer would not be conducive to good graft survival. The fact that they were able to choose good granulation tissue as graft sites migh suggest that the damaging event was followed by revascularisation in the 18 patients whose grafts were successful.

Our approach recognises the fact that in the elderly the deformability of red cells is reduced and as a result capillary perfusion is impaired. It is suggested that the healing of lesions might be enhanced by dietary supplementation to increase the deformability of red cells, thus improving capillary perfusion. Such an approach could be used in conjunction with pinch grafting. We have found that oil of evening primrose (Efamol) enhanced the healing of leg ulcers, ${ }^{2}$ and othe agents that improve blood rheology, such as eicosapentaenoic acid, might have similar effects Efamol contains $\gamma$-linolenic acid, a precursor to prostaglandin $E_{1}$, which improves the fluidity of the bilipid layer of erythrocyte membranes ${ }^{3}$ and improves their filterability. ${ }^{4}$ Eicosapentaenoic acid seems to have similar effects on red cells. ${ }^{56}$

Over the past two years I have photographed every seven or 14 days the leg lesions of 14 elderly patients taking three capsules of Efamol with each meal. Some of the lesions had existed for over 20 years, and they ranged in size from less than $1 \mathrm{~cm}^{2}$ to more than $170 \mathrm{~cm}^{2}$. During the period of observation the lesions of five patients healed, although in two cases new lesions developed within six months. The lesions of three other patients are close to healing, while the ulcers of eight are much smaller. Persistent infection or reinfection, or both, with pseudomonas has been the dominant factor in the lesions of the two remaining patients. In one the area of the ulcers alternated between episodes of healing and enlargement, and in the other the three large lesions (total area more than $170 \mathrm{~cm}^{2}$ ) have hardly changed in the past six months. The most intriguing change associated with the fatty acid supplementation has been a reduction in pain, as indicated by the use of fewer painkillers. This reduction in pain occurred whether or not evidence of healing was visible.

Though the basic mechanisms are not understood, the closure of these long term lesions seemed to follow one of two patterns. With the first, the appearance of a yellow scab around the edge of a lesion indicated epithelial cell activity as layers of epithelial cells were observed when the material was studied by electron microscopy. Eventually the yellow scab covered the lesion, with epithelialisation occurring underneath. Closure occurred in other cases by the formation of pale pink scar tissue advancing from localised sites around the margin. This type of repair seems to be associated with recurrent breakdown more often than the first type. These observations of apparent "epithelial energy" concur with the conclusion of Adair that "failure of epithelialisation is not due to any lack of epithelial cell production and that some other fundamental defect must be sought."

As some of the healed lesions in this small series included both medial and lateral malleolar ulcers, the already impressive results of $\mathrm{Mr}$ Poskitt and colleagues might be improved further if their patients were given dietary supplementation to 